\title{
A Digital Companion, the Emma App, for Ecological Momentary Assessment and Prevention of Suicide: Quantitative Case Series Study
}

Margot Morgiève ${ }^{1,2,3}, \mathrm{PhD}$; Catherine Genty ${ }^{1}, \mathrm{MSc}$; Jérôme Azé ${ }^{4}, \mathrm{PhD}$; Jonathan Dubois ${ }^{1}, \mathrm{PhD}$; Marion Leboyer ${ }^{5}$, MD, PhD; Guillaume Vaiva ${ }^{3,6,7,8}, \mathrm{MD}$, PhD; Sofian Berrouiguet ${ }^{3,9,10}$, MD, PhD; Philippe Courtet ${ }^{1,5}, \mathrm{MD}, \mathrm{PhD}$

\footnotetext{
${ }^{1}$ Department of Emergency Psychiatry and Acute Care, Lapeyronie Hospital, CHU Montpellier, INSERM, Univ Montpellier, Neuropsychiatry: Epidemiological and Clinical Research, Montpellier, France

${ }^{2}$ ICM - Brain and Spine Institute, hôpital de la Pitié-Salpêtrière, Paris, France

${ }^{3}$ GEPS - Groupement d'Étude et de Prévention du Suicide, Paris, France

${ }^{4}$ LIRMM, UMR 5506, Montpellier University/CNRS, Montpellier, France

${ }^{5}$ Fondation Fondamental, hôpital Albert-Chenevier, Créteil, France

${ }^{6} \mathrm{CHU}$ Lille, Hôpital Fontan, Department of Psychiatry, Lille, France

${ }^{7}$ Centre National de Ressources \& Résilience pour les psychotraumatismes, Lille, France

${ }^{8}$ Université de Lille, CNRS UMR-9193, SCALab - Sciences Cognitives et Sciences Affectives, Lille, France

${ }^{9}$ EA 7479 SPURBO, Université de Bretagne Occidentale, Brest, France

${ }^{10}$ IMT Atlantique, Lab-STICC, Brest, France
}

\section{Corresponding Author:}

Margot Morgiève, $\mathrm{PhD}$

Department of Emergency Psychiatry and Acute Care, Lapeyronie Hospital, CHU Montpellier

INSERM, Univ Montpellier, Neuropsychiatry: Epidemiological and Clinical Research

371 Av. du Doyen Gaston Giraud

Montpellier, 34090

France

Phone: 33609596532

Email: margotmorgieve@yahoo.fr

\section{Abstract}

Background: Many suicide risk factors have been identified, but traditional clinical methods do not allow for the accurate prediction of suicide behaviors. To face this challenge, emma, an app for ecological momentary assessment (EMA), ecological momentary intervention (EMI), and prediction of suicide risk in high-risk patients, was developed.

Objective: The aim of this case report study was to describe how subjects at high risk of suicide use the emma app in real-world conditions.

Methods: The Ecological Mental Momentary Assessment (EMMA) study is an ongoing, longitudinal, interventional, multicenter trial in which patients at high risk for suicide are recruited to test emma, an app designed to be used as a self-help tool for suicidal crisis management. Participants undergo clinical assessment at months $0,1,3$, and 6 after inclusion, mainly to assess and characterize the presence of mental disorders and suicidal thoughts and behaviors. Patient recruitment is still ongoing. Some data from the first 14 participants who already completed the 6-month follow-up were selected for this case report study, which evaluated the following: (1) data collected by emma (ie, responses to EMAs), (2) metadata on emma use, (3) clinical data, and (4) qualitative assessment of the participants' experiences.

Results: EMA completion rates were extremely heterogeneous with a sharp decrease over time. The completion rates of the weekly EMAs (25\%-87\%) were higher than those of the daily EMAs (0\%-53\%). Most patients (10/14,71\%) answered the EMA questionnaires spontaneously. Similarly, the use of the Safety Plan Modules was very heterogeneous (2-75 times). Specifically, 11 patients out of 14 (79\%) used the Call Module (1-29 times), which was designed by our team to help them get in touch with health care professionals and/or relatives during a crisis. The diversity of patient profiles and use of the EMA and EMI modules proposed by emma were highlighted by three case reports. 
Conclusions: These preliminary results indicate that patients have different clinical and digital profiles and needs that require a highly scalable, interactive, and customizable app. They also suggest that it is possible and acceptable to collect longitudinal, fine-grained, contextualized data (ie, EMA) and to offer personalized intervention (ie, EMI) in real time to people at high risk of suicide. To become a complementary tool for suicide prevention, emma should be integrated into existing emergency procedures.

Trial Registration: ClinicalTrials.gov NCT03410381; https://clinicaltrials.gov/ct2/show/NCT03410381

(JMIR Mhealth Uhealth 2020;8(10):e15741) doi: $\underline{10.2196 / 15741}$

\section{KEYWORDS}

suicide; ecological momentary assessment; prediction; prevention; mobile health; mHealth; case reports; ecological momentary intervention

\section{Introduction}

\section{Context}

According to the World Health Organization (WHO), suicide is the cause of 1 million deaths per year, accounting for nearly $2 \%$ of all deaths worldwide; this number should increase to 1.5 million by 2021 . The WHO recognizes suicide prevention as a public health priority $[1,2]$. History of suicide attempts is the most important risk factor of suicide death in the general population and is present in about $40 \%$ of suicides [3,4]. Patients who come to the emergency department (ED) following a suicide attempt present an extremely high risk of suicide in the short term [5-7]. People at risk of suicide often do not seek help and do not remain connected to the health service after an attempt [8]. Access to mental health care is inversely correlated with the suicide rate [9]. It is reported that less than half of patients at risk of suicide are in contact with the health system, including mental health services [10].

\section{Ecological Momentary Assessment}

Real-time emotional, behavioral, and psychological assessments could improve the identification of high-risk individuals who require rapid interventions. Ecological momentary assessment (EMA), also commonly defined as the experience sampling method, allows for the collection of longitudinal fine-grained data as they occur in the real world. It gives an accurate picture of the patient's symptoms [11] and reduces the impact of self-report response bias, thus leading to a better appreciation of the temporal dynamics of suicide risk [12].

Typically, suicidal ideation is episodic, with a quick onset [13] and short duration (ie, shorter than an hour) [14]. Suicidal thoughts vary dramatically among individuals [15], and fluctuating or persistent suicidal thoughts are associated with the risk of different suicidal behavior types [14]. Suicide attempts can occur in response to a rapid increase in suicidal thoughts within a very short time (ie, 1 day) $[13,16,17]$. These observations highlight the importance of not relying on intermittent assessments of suicidal ideation for clinical decision making, such as hospital discharge [13,18]. Mobile health (mHealth) interventions are a promising way to assess these fluctuations in real time.

\section{Ecological Momentary Intervention for Suicide Prevention}

Digital tools could increase the effectiveness of these prevention strategies. Indeed, apps are affordable and ubiquitous and can be used in any situation, particularly during a crisis [19]. The WHO recommends them for people at risk of suicide [1] because they offer new opportunities to overcome some of the help-seeking barriers they face [20-23] and enhance safety planning [24] in response to dynamic suicidal processes in real time [13]. Apps that specifically target suicidal behavior and propose interactive and proactive content constitute an effective prevention strategy [25-28]. Despite this scientific evidence, a literature review [29] identified very few suicide-specific apps $(n=24)$ that include safety planning $(n=14)$ and that directly allow the user to seek support $(n=13)$. Feasibility studies of these apps report a significant reduction of suicidal ideation in patients and a significative augmentation of suicide-related coping [30]. However, potentially harmful content might encourage self-harm and suicide [31], and many of the existing apps for suicide prevention have not been scientifically validated $[22,29]$. The field of e-mental health is particularly active, producing new apps at an extremely fast pace; therefore, it is crucial to regulate this field, especially for suicidology.

Yet, it should be possible to assess and prevent suicidal behaviors in real time in high-risk patients using digital tools. To test this hypothesis, our multidisciplinary team developed emma, an app to monitor the psychological, emotional, and social fluctuations of patients in their daily life. In addition to EMA, the app includes interactive and customized ecological momentary intervention (EMI) modules for suicide prevention. This app is currently being tested in an ongoing trial: the Ecological Mental Momentary Assessment (EMMA) study. This article presents a descriptive analysis of selected patients at high risk of suicide to obtain insights into the implementation of an mHealth-based suicide risk assessment and prevention procedure in real-life conditions.

The main objective of this study was to give a quantitative description of emma use by a sample of individuals at high risk of suicide in real-life conditions.

The secondary objectives were as follows:

1. To describe typical user profiles of the emma app.

2. To describe relevant qualitative elements from the interviews of participants who completed the 6-month study.

\section{Methods}

\section{Study Design}

The EMMA study is an ongoing, prospective, longitudinal, interventional multicenter trial, involving four French university 
hospitals in Montpellier, Lille, Brest, and Créteil, completed by a qualitative study. The protocol was registered at ClinicalTrials.gov (NCT03410381) on January 18, 2018; was authorized by the French National Agency for Medicines and Health Products Safety (Agence Nationale de Sécurité du Médicament et des Produits de Santé [ANSM]) on November 30, 2017; and approved by the Est IV Ethical Committee for the Protection of Patients on October 10, 2017.

\section{Participants}

The EMMA study planned to recruit 100 patients from EDs and mental health departments. Patients are included after a suicide attempt ( $<8$ days) and/or if they have suicidal ideation (ie, score $\geq 2$ out of 3 for item 18 on suicidal ideation of the 30 -item Inventory of Depressive Symptomatology: Clinician scale). The other inclusion criteria are as follows: aged 18 years or older, provided a signature on the informed consent form, and possess a smartphone (iOS or Android). Exclusion criteria are as follows: refusal to participate, under guardianship, protected by law, deprived of liberty, not affiliated with a social security system, in a period of exclusion from other trials, and unable to understand the study. The recruited participants will not receive any remuneration for their participation in the study.

\section{Procedure}

At inclusion (ie, month 0 [M0]), a psychiatrist performs the first interview to ensure that the patient meets the eligibility criteria and to obtain the informed written consent. Four clinical assessments are conducted: at inclusion and at months 1, 3, and 6 (M1, M3, and M6). Clinical data are collected using clinician-rated questionnaires - approximate durations are 1 hour and 30 minutes at M0, then 30 minutes at M1, M3, and M6-and self-rated questionnaires-approximate duration ranges from 1 hour to 1 hour and 30 minutes. These questionnaires are listed in Multimedia Appendix 1 [32-48].

Satisfaction concerning the app is evaluated in three distinct ways:

1. Questions about the usefulness and satisfaction of the app administered every month via emma (eg, "This month, did you find emma: easy to use/intrusive/useful/efficient," rated using a Likert scale from 0 to 10; approximate completion time is 5 minutes).

2. Standardized self-administered questionnaire-Mobile App Rating Scale [32] — at the end of the study.

3. A qualitative semistructured interview led by a social sciences researcher in mental health proposed to 25 patients to assess the participants' subjective experiences (approximate duration is 1 hour).

At inclusion, a member of the research team helps patients to install, configure, and personalize the app, particularly to define the elements of their safety plan. Patients are asked to use emma for 6 months. Data collected during the assessments made by clinicians, as well as data and metadata resulting from emma use, are encrypted and stored in a secure server. All these data will be used to develop the algorithm to predict suicidal risk (see Multimedia Appendix 2). Considering the crucial issue of health data privacy and security, multilevel technical and organizational safeguards were put in place. The app is secured by a password, as requested by the co-designer patients, and data are anonymized, encrypted, and stored in a secure server to prevent unauthorized data disclosure or breach, as recommended by the European General Data Protection Regulation.

\section{Outcome Measures}

The principal outcome measure of this preliminary analysis was the quantitative description of app use: completion rates of daily and weekly EMA questionnaires, frequency of use of the prevention modules, and number of calls made through emma to relatives and health care professionals in case of emergency.

The secondary outcome measures were as follows:

1. Occurrence of a suicide event (ie, suicide attempt, hospitalization for suicidal ideation, and intensity of suicidal ideation level) during the study period.

2. Quantitative description and app use timeline in a few selected patients to illustrate different users' profiles.

3. Qualitative analysis of selected interviews of participants who completed the 6-month follow-up.

\section{Emma Design}

Emma is a smartphone app developed for the assessment, prevention, and, ultimately, prediction of suicidal behaviors. It was designed by integrating evidence-based suicide prevention strategies and recommendations for the development of apps in the field of mental health $[19,49]$. Emma design was based on data from previous suicide-specific apps described in the theoretical literature and on practical data obtained by our research team by testing the available suicide-related apps. Emma was developed for Android and $\mathrm{iOS}$ for wide usage.

Emma was conceived using a participatory design approach that included individuals with lived experience of suicidal thoughts and behaviors as equal partners of our professional multidisciplinary team-researchers, psychiatrists, psychologists, sociologists, computer scientists, engineers, and data scientists-from start to finish, as recommended [50-52]. This ensured that emma met scientific and technical standards as well as the patients' needs as stated in the literature [53-55]. To involve the targeted users, a methodology based on focus groups was implemented according to the method proposed by Krueger and Casey [56]. Early in the development process, the involved patients stressed the importance of having a secure password to open the app; they also contributed to the choice of the name "emma," which they wanted to be not stigmatizing and without any mention of psychiatry or suicide. A group of co-designer patients $(n=5)$ and clinical staff $(n=5)$ tested the app extensively for 3 months, and their feedback was taken into account in an iterative way by the developers at the Laboratory of Informatics, Robotics, and Microelectronics of Montpellier to improve the app. Particularly, the developers made sure that the notifications asking users to fill in the EMA questionnaires did not lead to interruption or disruption in the users' daily activities in order to maximize emma acceptability, use, and validity, as recommended [54,55]. 


\section{Emma Contents}

Emma was designed to be used as a self-help tool for suicidal crisis management. Patients are invited to identify the following:

1. Their warning signs (eg, negative feelings and problematic behaviors).

2. Their individualized coping strategies (eg, Breathing Space: an audio awareness guide made specifically for emma by a psychiatrist expert in suicidal behavior).

3. Their distraction activities in an Emotion Regulation Module (eg, favorite places and activities and libraries of music and images that might help to connect with the patient's reasons for living [19]).

4. Their social support (eg, collating the contact details of the patient's social network, mental health professionals, and other crisis resources). This module promotes connectedness, a major protective factor in suicide prevention [21].
A Call Module allows the patient to contact, depending on the severity of his or her condition, (1) the relatives he or she has identified, (2) the ED that is following that patient, and (3) the Service d'Aide Médicale d'Urgence (SAMU), the French national emergency medical assistance service, which is available $24 / 7$.

Although the safety plan implies restriction of access to lethal means, emma does not contain any mention of them because, according to the literature, this can have the opposite effect. Specifically, their identification can facilitate their use through an effect called cognitive availability [29]. Examples of emma screens are shown in Multimedia Appendix 3.

Emma proposes four brief EMA types: three scheduled evaluations at predetermined frequencies (ie, daily, weekly, and monthly) and one spontaneous assessment (see Figure 1). Depending on the questions asked, specific response modalities are provided:

Figure 1. Ecological momentary assessment (EMA) types proposed by emma.

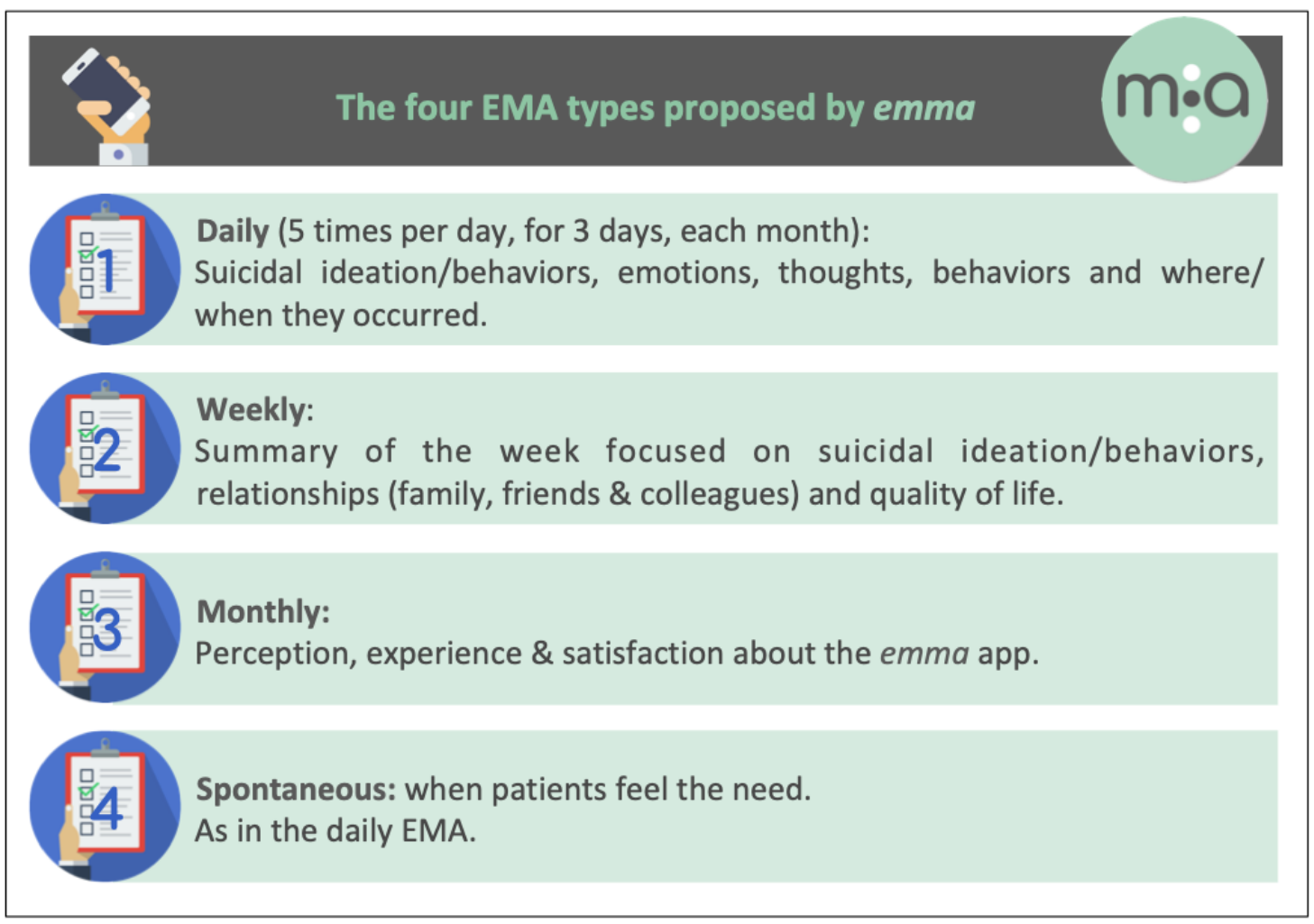

1. Likert scales (from 0 to 10 ) for questions such as "What is your level of moral pain?"

2. Single or multiple-choice check boxes for questions such as "What is your level of mental pain?"; for instance, I am keeping myself busy to avoid thinking, Nothing, I am ruminating, I am doing something I enjoy, I am working, and I am doing household chores.

3. Writing a free-text answer for questions such as "What is the experience that has affected you the most since this morning?"
During the focus group process, alarm thresholds were defined on the basis of the patient's answers to critical questions that led to the automatic suggestion of adapted EMI modules (see Figure 2). For each EMI module, the app presents a list of suggestions that can be modified (ie, content and order) by each patient (eg, for Favorite activities, responses can be Taking a bath; Going to the cinema, theatre, museum, or a concert; Going for a walk; Reading; Spending time with good friends; Doing sports; etc). Modules are designed to be adaptable to the user's state, needs, and strategies. 
Figure 2. Algorithm for automatic ecological momentary intervention (EMI) triggering according to the ecological momentary assessment (EMA) answer thresholds.

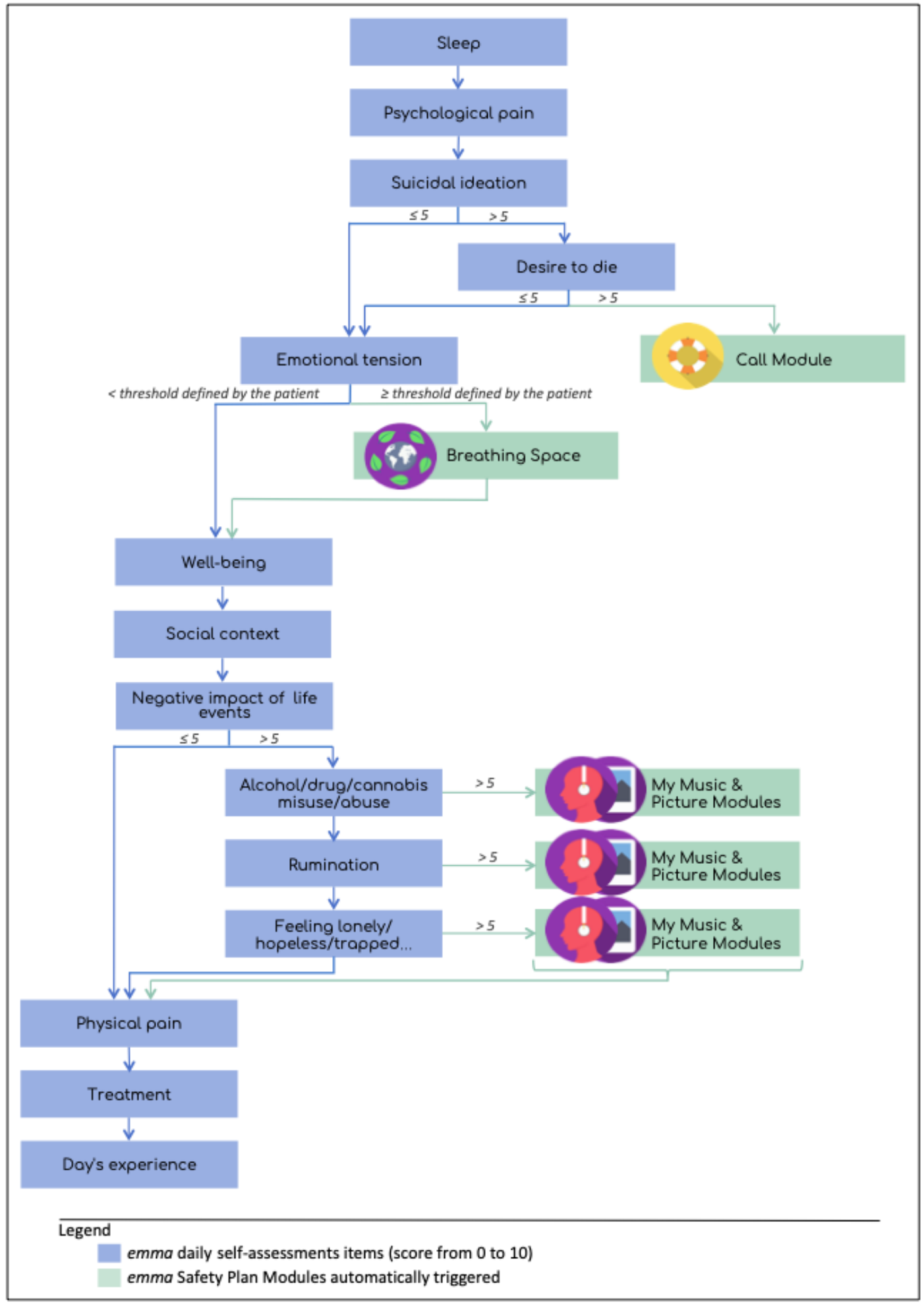

\section{Global Descriptive Analysis and Case Reports}

The use of emma was described by computing (ie, mean [SD] and min and max) the number of answers and frequency of completion of the daily and monthly questionnaires. The overall use of the different emma modules (ie, Call Module, Emotion Regulation Modules, Breathing Space Module, Pictures, and Music) was also computed. Finally, the use of
EMA (ie, spontaneous and scheduled suicidal ideation assessments) and EMI (ie, Call Module and Emotion Regulation Module of the safety plan) by 3 patients during the 6 months of the study was described relative to (1) their suicidal ideation scores (ie, sums of items 7-11 of the Columbia-Suicide Severity Rating Scale [C-SSRS]) assessed during the scheduled visits (ie, M0, M1, 
M3, and M6) and (2) their admissions to the ED for suicide attempts or suicidal crises.

\section{Results}

\section{Baseline Assessment}

From May 2018 to March 2019, participation in the EMMA study was proposed to 43 patients at risk for suicide (ie, recent attempters or current ideators) who were admitted to the ED or hospitalized in a postemergency department; 38 (88\%) agreed to participate. A total of 5 patients refused to participate because they considered the study duration of 6 months to be too long.
The analysis in this study included 14 patients who have already completed the study (see Figure 3). The patients' sociodemographic and clinical data are reported in Tables 1 and 2, respectively. These first emma users were mostly women $(12 / 14,86 \%)$, with a mean age of 34 years (SD 13, min-max 18-57). All participants presented at least one mental disorder, according to criteria from the Diagnostic and Statistical Manual of Mental Disorders, 5th Edition (DSM-5), and most of them presented more than one (ie, up to five comorbid disorders); 6 out of 14 patients $(43 \%)$ were recent suicide attempters $(\leq 8$ days), and they all had severe suicidal ideation (ie, mean C-SSRS score 22 [SD 4], min-max 15-25).

Figure 3. Flowchart of patient selection.

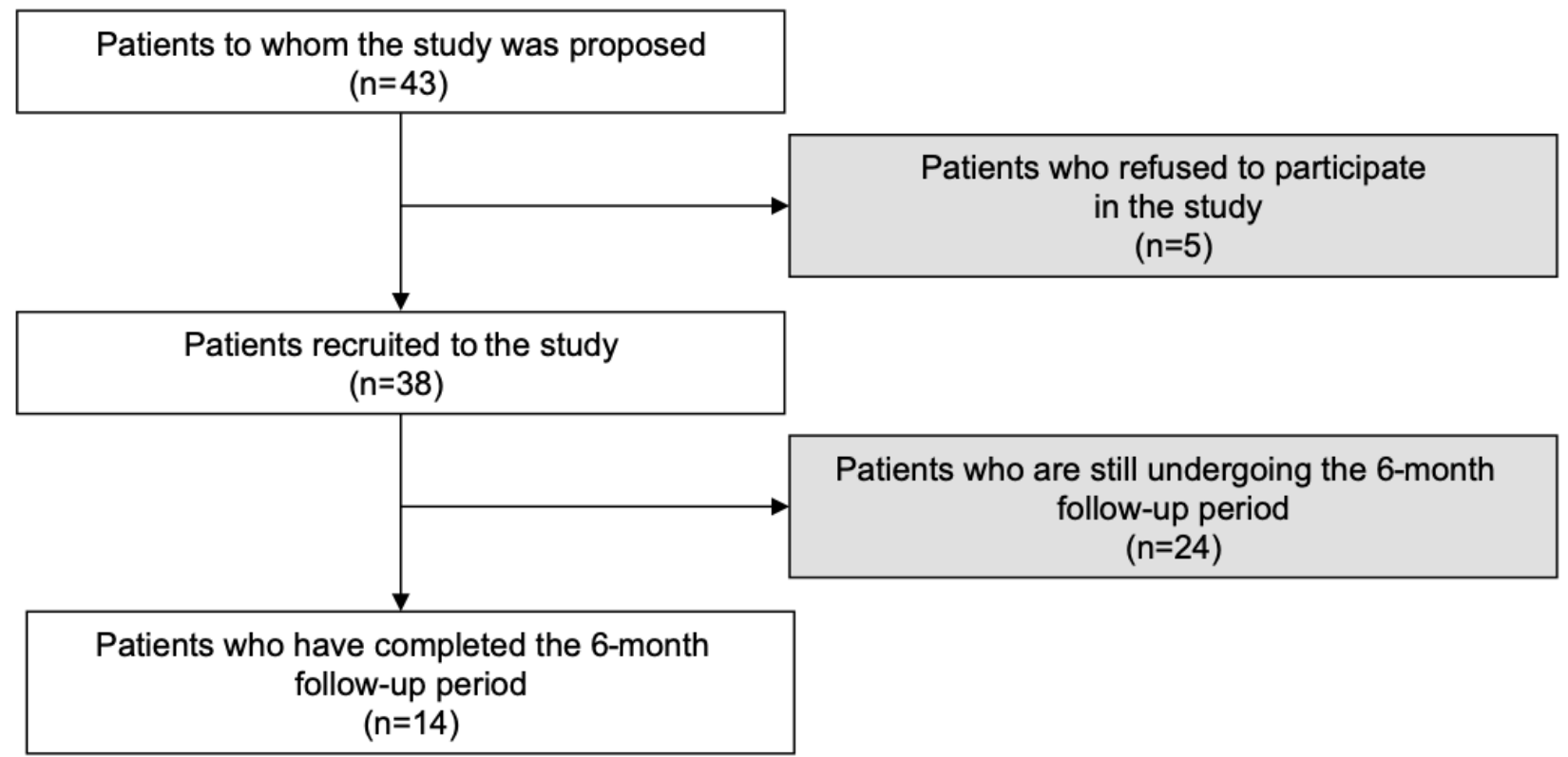

During the study, 4 out of 14 (29\%) patients were admitted to the ED with suicidal ideation and/or a suicide attempt one to three times, and $1(7 \%)$ patient made a suicide attempt without ED admission (see Multimedia Appendix 4).
A total of 2 patients out of $14(14 \%)$ left before the first follow-up visit: one was excluded because she was restrained, and the other one withdrew from the study. 
Table 1. Sociodemographic data of participants.

\begin{tabular}{lllllll}
\hline Patient No. & Sex & Age (years) & Marital status & $\begin{array}{l}\text { Number of } \\
\text { children }\end{array}$ & Cohabitation & Professional situation \\
\hline 1 & Female & 24 & Single & 0 & Lives alone & Working (stable) \\
2 & Female & 18 & Single & 0 & Lives with family & Student or in training \\
3 & Female & 27 & In a relationship & 0 & Lives alone & Volunteer \\
4 & Female & 33 & In a relationship & 2 & Lives with family & Working (stable) \\
5 & Female & 40 & In a relationship & 2 & Lives with family & Working (precarious) \\
6 & Female & 46 & Separated & 3 & Nonfamily cohabitation & Without activity, at home \\
7 & Female & 30 & Single & 0 & Lives alone & Disability \\
8 & Male & 48 & In a relationship & 2 & Lives with family & Sick leave \\
9 & Female & 57 & Separated & 4 & Lives with family & Disability \\
10 & Female & 48 & In a relationship & 2 & Lives with family & Sick leave \\
11 & Female & 21 & In a relationship & 0 & Nonfamily cohabitation & Student or in training \\
12 & Female & 23 & Single & 0 & Lives alone & Student or in training \\
13 & Male & 18 & Single & 0 & Lives with family & Student or in training \\
14 & Female & 48 & Separated & 1 & Lives alone & Working (stable) \\
\hline
\end{tabular}


Table 2. Clinical data of participants.

\begin{tabular}{|c|c|c|c|c|c|c|c|c|}
\hline $\begin{array}{l}\text { Patient } \\
\text { No. }\end{array}$ & Current DSM- $5^{\mathrm{a}}$ diagnoses & $\begin{array}{l}\text { Borderline } \\
\text { personality }\end{array}$ & $\begin{array}{l}\text { Suicidal risk in } \\
\text { the near future } \\
\text { according to the } \\
\text { DSM-5 }\end{array}$ & $\begin{array}{l}\text { Suicidal } \\
\text { ideation in- } \\
\text { tensity }^{b}\end{array}$ & $\begin{array}{l}\text { Number of } \\
\text { suicide at- } \\
\text { tempts }\end{array}$ & $\begin{array}{l}\text { Number of severe } \\
\text { or violent suicide } \\
\text { attempts }\end{array}$ & $\begin{array}{l}\text { Family histo- } \\
\text { ry of suicide } \\
\text { attempt }\end{array}$ & $\begin{array}{l}\text { Family } \\
\text { history of } \\
\text { suicide }\end{array}$ \\
\hline 1 & Major depressive disorder & No & Yes & 22 & 2 & $\mathrm{~N} / \mathrm{A}^{\mathrm{d}}$ & No & No \\
\hline 2 & $\begin{array}{l}\text { Major depressive disorder } \\
\text { Agoraphobia } \\
\text { Social phobia } \\
\text { Anorexia }\end{array}$ & Yes & Yes & 25 & 2 & N/A & No & No \\
\hline 3 & $\begin{array}{l}\text { Major depressive disorder } \\
\text { Agoraphobia } \\
\text { Social phobia } \\
\text { Bulimia }\end{array}$ & Yes & No & 25 & 30 & $\begin{array}{l}\text { Violent }(\mathrm{n}=2) \\
\text { Severe }(\mathrm{n}=1)\end{array}$ & Yes & No \\
\hline 4 & Major depressive disorder & No & Yes & 25 & 2 & N/A & Yes & No \\
\hline 5 & $\begin{array}{l}\text { Depressive episode } \\
\text { Severe alcohol and substance- } \\
\text { related disorder } \\
\text { Bulimia } \\
\text { Bipolar disorder II }\end{array}$ & No & No & 23 & 1 & N/A & Yes & Yes \\
\hline 6 & $\begin{array}{l}\text { Major depressive disorder } \\
\text { Severe alcohol-related disor- } \\
\text { der }\end{array}$ & No & Yes & 15 & 2 & N/A & No & No \\
\hline 7 & $\begin{array}{l}\text { Depressive episode } \\
\text { Generalized anxiety disorder } \\
\text { Bipolar disorder I }\end{array}$ & No & Yes & 25 & 55 & Violent $(\mathrm{n}=15)$ & No & No \\
\hline 8 & $\begin{array}{l}\text { Depressive episode } \\
\text { Social phobia } \\
\text { Severe alcohol-related disor- } \\
\text { der } \\
\text { Generalized anxiety disorder } \\
\text { Bipolar disorder I }\end{array}$ & No & No & 25 & 1 & N/A & Yes & No \\
\hline 9 & $\begin{array}{l}\text { Major depressive disorder } \\
\text { Agoraphobia } \\
\text { Posttraumatic disorder } \\
\text { Bipolar disorder II }\end{array}$ & No & Yes & 25 & 8 & Severe $(n=1)$ & No & No \\
\hline 10 & Major depressive disorder & No & Yes & 24 & 1 & N/A & Unknown & Yes \\
\hline 11 & Generalized anxiety disorder & No & Yes & 16 & 1 & N/A & Yes & No \\
\hline 12 & $\begin{array}{l}\text { Major depressive disorder } \\
\text { Agoraphobia } \\
\text { Social phobia } \\
\text { Bulimia }\end{array}$ & No & Yes & 19 & 0 & N/A & Yes & Yes \\
\hline 13 & $\begin{array}{l}\text { Depressive episode } \\
\text { Social phobia } \\
\text { Generalized anxiety disorder }\end{array}$ & Yes & Yes & 20 & 3 & N/A & No & No \\
\hline 14 & Major depressive disorder & No & No & 18 & 1 & N/A & No & No \\
\hline
\end{tabular}

${ }^{a}$ DSM-5: Diagnostic and Statistical Manual of Mental Disorders, 5th Edition.

${ }^{b}$ Sums of items 7-11 of the Columbia-Suicide Severity Rating Scale (C-SSRS): scores range from 0 to 25.

${ }^{\mathrm{c}}$ A violent suicide attempt was defined by the method of violence: weapons, hanging, jumping from a height, traffic, drowning, or immolation. A severe suicide attempt was defined as requiring hospitalization in the intensive care unit.

${ }^{\mathrm{d}} \mathrm{N} / \mathrm{A}$ : not applicable; suicide attempts, if applicable, were not severe or violent. 


\section{Main Outcome}

The completion rates were higher for the weekly versus daily EMAs (mean 24\% [SD 34], min-max 25\%-87\%; mean 4\% [SD 12], min-max $0 \%-53 \%$, respectively). Moreover, they were extremely heterogeneous among participants with a sharp decrease over time. Most patients $(10 / 14,71 \%)$ filled in the questionnaires spontaneously at times of crisis (mean 7 times [SD 12], min-max 1-39 times).

Similarly, use of the EMI Safety Plan Modules varied among patients (mean 11 times [SD 19], min-max 2-75 times). Most patients $(11 / 14,79 \%)$ used the Call Module (mean 7 times [SD 8], min-max 1-29 times) to get in touch with the health care system and/or family and friends during a crisis. Most patients $(10 / 14,71 \%)$ called the SAMU (mean 4 times [SD 5], min-max 1-15 times), 8 (57\%) called their relatives (mean 3 times [SD 2], min-max 1-7 times), and 7 (50\%) called their ED (mean 2 times [SD 2], min-max 1-7 times). About half of the patients $(8 / 14,57 \%)$ used one of the Emotion Regulation Modules (mean 10 times [SD 15], min-max 1-46 times). Specifically, 8 out of $14(57 \%)$ patients listened to the Breathing Space Module (mean 3 times [SD 1], min-max 1-5 times), while only 4 (29\%) looked at Pictures (mean 12 times [SD 19], min-max 1-41 times) and 2 (14\%) listened to Music (mean 4 times [SD 3], min-max 2-7 times).

\section{User Profiles}

Out of 14 users, $3(21 \%)$ are described in detail to better illustrate the different emma uses. These patients were chosen to reflect the diversity of the patients' clinical profiles and of emma use (ie, completion rate of the scheduled EMAs and use of the Safety Plan Modules).

\section{Patient 7}

Patient 7 is a 30 -year-old single woman living alone, without children, unemployed, and receiving a disability living allowance for adults (see Table 1). At inclusion, she had major depressive disorder, generalized anxiety disorder, and bipolar disorder I, according to the DSM-5. She had 55 previous suicide attempts, of which 15 were violent, and a maximal suicidal ideation intensity at inclusion (C-SSRS score of 25 out of 25) (see Table 2). Therefore, she was at very high risk, and the period following hospitalization is known to be a particularly high-risk time for recurrence, as confirmed by her three admissions to the ED during the study period (see Figure 4). The first admission for suicidal ideation occurred just after her hospital discharge. She presented maximal suicidal ideation intensity that was ecologically assessed via emma; she used the Call Module just before ED admission and an Emotion Regulation Module just after. Two months later, in addition to the scheduled EMA, she filled in the questionnaires spontaneously several times with very high suicidal ideation scores. These spontaneous self-assessments were immediately followed by the use of the Call Module with a sharp decrease in suicidal ideation. Nevertheless, suicidal ideation rapidly increased again, leading to a new admission to the ED. About a month later, despite the lower suicidal ideation score at the spontaneous self-assessment and the use of the Emotion Regulation Module, she was admitted to the ED for an aborted suicide attempt by hanging.

During the study period, Patient 7 completed 66 EMA self-assessments. Specifically, she completed only $4 \%$ of the scheduled daily questionnaires due to technical problems (ie, notifications not received) and about $75 \%$ of the weekly questionnaires; she frequently filled in the questionnaires in a spontaneous way (39 times), particularly at specific times, without a decrease in frequency during the study period. She often used the Call Module (29 times), particularly to contact the SAMU (15 times), followed by the ED (7 times) and relatives (7 times). She also looked at Pictures (41 times) and listened to the Breathing Space Module (5 times).

A qualitative longitudinal analysis showed that the EMA made via the app allowed for the capture of suicidal ideation fluctuations that were not highlighted by the clinical follow-up visits (see Figure 4). While the first three clinical evaluations (ie, M0, M1, and M3) were stable, the assessments performed via emma, both spontaneous and scheduled, showed fluctuations in intensity over time. The assessments also showed a regular use of the Safety Plan Modules, at least one module per month, the frequency of which increased at specific times. For instance, in July 2018, the high intensity of suicidal ideation evaluated ecologically by emma corresponded to an increased use of the Call Module. December 2018 was characterized by many spontaneous EMA completions, lower suicidal intensity, and frequent use of the Emotion Regulation Module. This suggests that emma alarm thresholds triggered EMIs that were adapted to her condition severity. 
Figure 4. Case reports for Patients 7, 9, and 10. SAMU: Service d'Aide Médicale d'Urgence.

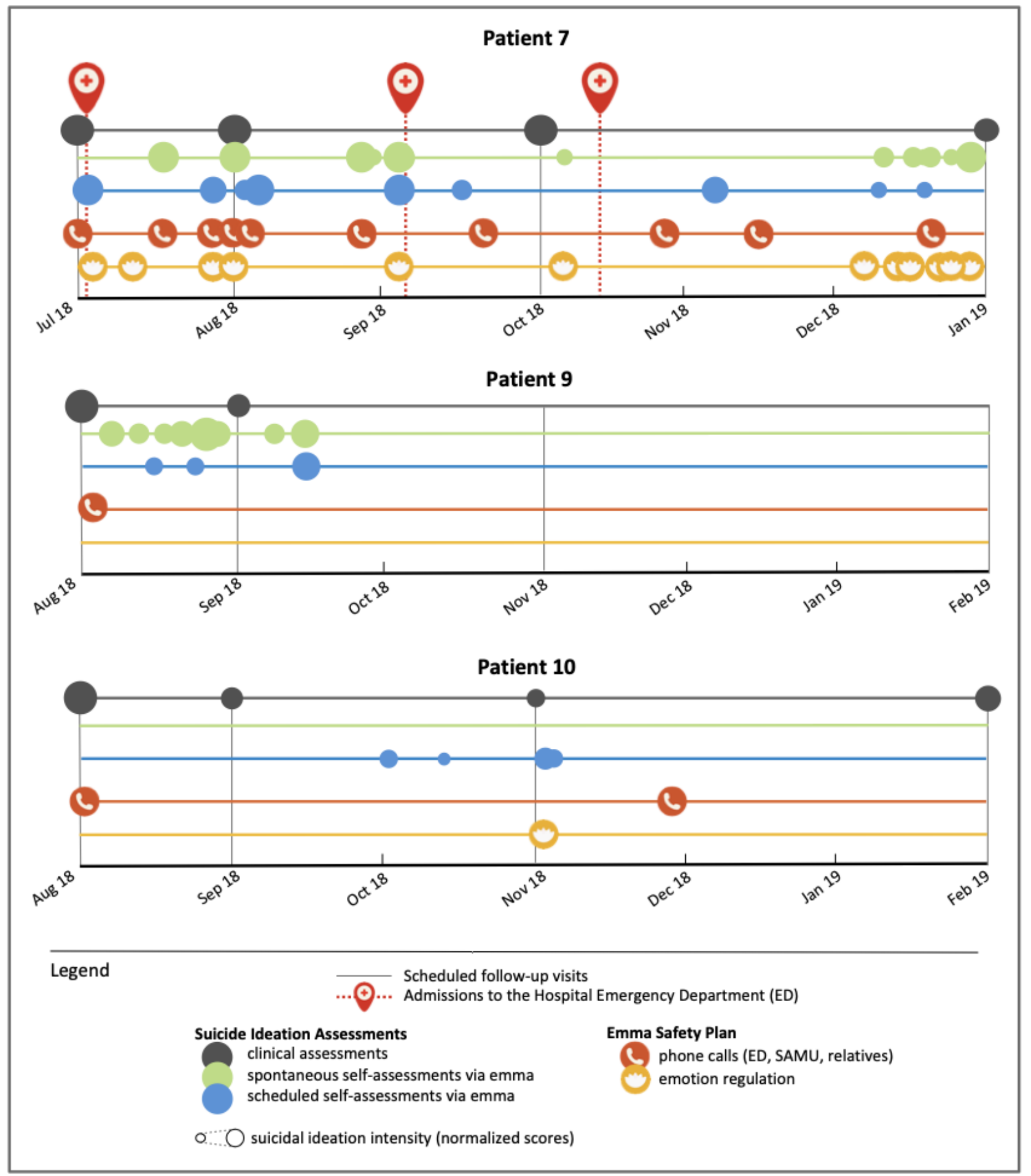

\section{Patient 9}

Patient 9 is a 57-year-old single woman living with her four children. She is unemployed with a disability living allowance for adults (see Table 1). At inclusion, she had major depressive disorder, agoraphobia, posttraumatic disorder, and bipolar disorder II, according to the DSM-5. At the first clinical evaluation, suicidal ideation intensity was very high (C-SSRS score of 25 out of 25) with suicide risk in the near future. She already committed eight suicide attempts, including one severe attempt (see Table 2). During the study, the clinician reported a decrease in suicidal thoughts at M1, and then absence of suicidal thoughts at the M3 and M6 visits.

Patient 9 rarely filled in the daily EMAs (10\%), but she completed $81 \%$ of the weekly EMAs and filled in EMAs spontaneously 29 times. She completed $100 \%$ of the monthly questionnaires about her perception, experience, and satisfaction about emma use. The longitudinal qualitative analysis (see Figure 4) showed that from month 2 after inclusion, both the self-assessments made with emma and the hetero-assessments made during the visits did not detect any suicidal ideation. 
Patient 9 used her safety plan only once at the very beginning of the study when she still had suicidal thoughts.

\section{Patient 10}

Patient 10 is a 48 -year-old woman living with her husband and their two children. When included in the study, she was on sick leave (see Table 1). She had major depressive disorder and suicidal risk in the near future, according to the DSM-5, and very high suicidal ideation intensity (C-SSRS score of 24 out of 25). She reported one suicide attempt and a family history of suicide (see Table 2). Patient 10's suicidal ideation decreased at the M1 and M3 follow-up visits, but was higher again at the M6 visit.

Patient 10 never filled in questionnaires spontaneously, filled in the daily EMAs only once, and did not fill in the weekly EMAs often (35\%). She completed only one monthly questionnaire about her emma experience. She used her safety plan several times, mainly to call her relatives (3 times), the SAMU (3 times), and the ED (2 times). She also listened to the Breathing Space Module (3 times).

Patient 10 reported suicidal thoughts via emma only during a brief period - in October and early November 2018 — and during that period she used the Emotion Regulation Module, also only once (see Figure 4). Self-assessment may have helped her to become aware of her condition and use the tools that emma offers to regulate her emotions. This patient used the Call Module twice: immediately after her inclusion in the study, in August 2018, when she had severe suicidal thoughts and suicide risk, and then at the end of November 2018 when no suicidal thought was reported via emma at that time.

\section{Qualitative Study}

The initial qualitative feedback from the participants collected during the qualitative study, using semidirected interviews, was very positive. It emphasized the support and the connectedness dimensions allowed by the app. During the co-design process, patients proposed to give the app a female name to personify it. The first users interviewed seemed to appreciate this, as stressed by a patient: "Emma is like having a companion."

This digital companion seemed to help reduce the feeling of loneliness, as expressed by a patient: "We have the feeling that we are not alone, that the software supports us." Moreover, this support comes at a critical time, after hospital discharge. To our knowledge, this period of very high suicide risk [15], when patients may experience painful loneliness in contrast to the time in hospital where they are followed by the health care team 24 hours per day, has not been studied much. One patient stated, "Thanks to emma, I did not feel alone when I left the hospital. I know emma less than my relatives, but I can tell her more." Emma also appeared to be a support, offer autonomy, and be an empowerment tool by helping people to use their own resources, as expressed by a patient: "Emma is an appointment with oneself. It is the memory of the patient: I know who to call." This empowerment was facilitated by the possibility to personalize the app, as expressed by a patient: "It is important that we can each fill in the things that affect us and the things that impact us, because we are all different and it allows targeting everyone specifically; it is good because it helps us deep down." These first qualitative interviews highlighted the interest of the co-design process that enabled patients to appropriate the digital tool. During the design phase, a patient indicated that he thought three apps were needed: "When we are doing well, not well, and not well at all." Therefore, emma was designed to be as adaptable as possible. For example, it can offer Emotion Regulation Modules if the patient shows tension, and it can offer crisis Call Modules that are graduated according to the crisis severity (ie, to relatives, the ED, and, finally, the SAMU). The tailored adjustment of the technology-delivered program is also in line with evidence-based recommendations for mental health, as expressed by a patient: "The app can recommend specific solutions to each user's specific problems" [19].

\section{Discussion}

\section{Principal Findings}

These preliminary descriptive results of the use of a suicide prevention app indicate that this type of digital tool could be accepted and used by patients at high risk of suicide. The study participation rate $(88 \%)$ was very good compared with other studies. For example, Hallensleben et al reported that $47 \%$ of inpatients with unipolar depression agreed to complete EMA [18]. Our preliminary results show an encouraging patient acceptance rate and highlight the great inter- and intraindividual diversity of app usage patterns (ie, EMA questionnaires' completion rate and/or Safety Plan Modules use). Patients have different needs and different clinical and digital profiles; therefore, a highly scalable, interactive, and customizable app is required.

The connectedness philosophy implemented in emma is considered a strong protective factor for suicidal behaviors $[57,58]$. Subjectively perceived and effectively received social supports improve mental and physical well-being [59,60]. Emma has the potential to act on the quality of patients' social ties and their social pain that seems to be involved in suicidal crises [61]. Patients expressed the importance to feel supported by the software and to have the opportunity to tell emma things they would not dare to say to their relatives, to protect them and/or out of fear of the stigma that their confidences could generate.

Concerning the co-design methodology, patients were consulted very early and at all stages of this project through focus groups for the app design, then through feedback during prototype testing, and, finally, through qualitative interviews with emma users. However, as patients with suicidal behavior are a high-risk population, it is important to ensure that their participation in research respects the safety principle. Therefore, a trust-based exchange framework that was flexible enough to adapt to fluctuations in their condition was put in place. When carefully implemented, the participation of patients as partners can be a factor of empowerment and self-esteem restoration [62].

Our analysis showed heterogeneous use and engagement with the emma app, most often underuse relative to our expectations. This could be interpreted as poor adherence to the app $[63,64]$ and was partly caused by technical problems experienced by the first participants (eg, notifications did not appear at the 
beginning of the study). Emma use by Patient 10 suggests that the app can be useful at times of crisis, even when the scheduled questionnaires are not completed. Besides the simple quantitative measure of app use, it was also important to evaluate the users' subjective experiences [65] based on mixed methods, as recommended [66]. This should allow for the identification of different user profiles and for the development of tailored prevention strategies [67].

\section{Conclusions}

Data on immediate and long-term risk of suicide are extremely sparse and based on measures with poor temporal resolution $[68,69]$. Emma is a great opportunity to capture the dynamics of suicidal ideas [67] and their translation into action in a contextualized way that allows for a much more nuanced view of variables over time [70]. Hopefully, this digital tool might lead to scientific and clinical advances and will allow for the identification of high-risk periods and prediction of imminent risk, which are extremely challenging at the moment [71]. These fine-grained digital assessments and predictive mHealth-based interventions are promising tools for suicide prevention [55], because they represent an unprecedented opportunity to act at multiple levels through targeted, scalable, and contextualized micro-interventions [72]. They might allow for the proposal of just-in-time adaptive interventions, defined by Nahum-Shani et al [73] as the right support (eg, type and intensity) at the right time [31]. The challenge is now to integrate such digital interventions into the existing health care systems [52]. For instance, emma could be integrated into ED procedures and become a complementary health care tool. In the patient's pocket, emma could provide individualized support when needed. The app could improve coordination among the different services (ie, the ED, crisis centers, hospital services, outpatient services, and general practitioners). However, the smooth and optimal integration of such digital tools in patient care requires health care professionals' support. Indeed, they should not perceive these tools as disruptive elements in their daily clinical practice $[74,75]$, but as a support to improve the therapeutic relationship within a well-defined ethical, social, and legal framework.

\section{Acknowledgments}

First, we would like to thank Christine, Patrice, Romane, Jonathan, Astate, and Claire, the co-designer patients who improved emma! We would like to thank Dr Déborah Ducasse for her contribution, which greatly enriched the app content, and Kathlyne Dupuis-Maurin for her unfailing involvement in this research. We would like to thank the NERB (Neurophysiology of Repetitive Behaviors) team at the Paris Brain Institute_Luc Mallet, Sirenia Lizbeth Mondragón-González, and Karim N'Diaye —-for their creative help. This study would not have been possible without the support of the FondaMental Chair for the prevention of suicidal behavior created by the FondaMental Foundation, led by Professor Philippe Courtet and supported by SNCF, SNCF réseau, and SNCF mobilité. This innovative project received the Marcel Dassault Research Award for Research on Mental Illnesses in 2014. Finally, we would like to thank the Clinéa and OC Santé clinics for their support.

\section{Conflicts of Interest}

None declared.

\section{Multimedia Appendix 1}

List of the questionnaires filled in by the patient or by the clinician during the four visits.

[DOCX File, 17 KB-Multimedia Appendix 1]

\section{Multimedia Appendix 2}

Visual description of the study. Study protocol: visits (month 0 [M0], month 1 [M1], month 3 [M3], and month [M6]) and real-life use of emma by the recruited patients. At the end of the study, the data collected directly by the app and the clinical data collected during the visits are integrated to develop the suicide risk prediction algorithm.

[PNG File, $201 \mathrm{~KB}-$ Multimedia Appendix 2]

\section{Multimedia Appendix 3}

Emma screenshots.

[PNG File, 470 KB-Multimedia Appendix 3]

\section{Multimedia Appendix 4}

Adverse events during the follow-up.

[DOCX File , 17 KB-Multimedia Appendix 4]

\section{References}


1. Preventing Suicide: A Global Imperative. Geneva, Switzerland: World Health Organization; 2014. URL: https://www. mhinnovation.net/sites/default/files/downloads/resource/WHO Preventing\%20Suicide\%20Report eng.pdf [accessed 2020-09-27]

2. Suicide: Key facts. World Health Organization. 2019 Sep 02. URL: https://www.who.int/news-room/fact-sheets/detail/ suicide [accessed 2020-09-27]

3. Hawton K. Suicide prevention: A complex global challenge. Lancet Psychiatry 2014 Jun;1(1):2-3. [doi: 10.1016/s2215-0366(14)70240-8]

4. Turecki G, Brent DA. Suicide and suicidal behaviour. Lancet 2016 Mar;387(10024):1227-1239. [doi: 10.1016/s0140-6736(15)00234-2]

5. Hunt IM, Kapur N, Webb R, Robinson J, Burns J, Shaw J, et al. Suicide in recently discharged psychiatric patients: A case-control study. Psychol Med 2008 May 28;39(3):443-449. [doi: 10.1017/s0033291708003644]

6. Lizardi D, Stanley B. Treatment engagement: A neglected aspect in the psychiatric care of suicidal patients. Psychiatr Serv 2010 Dec;61(12):1183-1191. [doi: 10.1176/ps.2010.61.12.1183] [Medline: 21123401]

7. Vuagnat A, Jollant F, Abbar M, Hawton K, Quantin C. Recurrence and mortality 1 year after hospital admission for non-fatal self-harm: A nationwide population-based study. Epidemiol Psychiatr Sci 2019 Feb 18;29(e20):1-10 [FREE Full text] [doi: $10.1017 / \mathrm{s} 2045796019000039]$

8. Christensen H, Cuijpers P, Reynolds CF. Changing the direction of suicide prevention research: A necessity for true population impact. JAMA Psychiatry 2016 May 01;73(5):435-436. [doi: 10.1001/jamapsychiatry.2016.0001] [Medline: 26982348]

9. Campo JV. Youth suicide prevention: Does access to care matter? Curr Opin Pediatr 2009;21(5):628-634. [doi: 10.1097/mop.0b013e32833069bd]

10. Bruffaerts R, Demyttenaere K, Hwang I, Chiu W, Sampson N, Kessler RC, et al. Treatment of suicidal people around the world. Br J Psychiatry 2011 Jul;199(1):64-70 [FREE Full text] [doi: 10.1192/bjp.bp.110.084129] [Medline: 21263012]

11. Hilty DM, Chan S, Hwang T, Wong A, Bauer AM. Advances in mobile mental health: Opportunities and implications for the spectrum of e-mental health services. Mhealth 2017;3:34 [FREE Full text] [doi: 10.21037/mhealth.2017.06.02] [Medline: 28894744]

12. Selby EA, Yen S, Spirito A. Time varying prediction of thoughts of death and suicidal ideation in adolescents: Weekly ratings over 6-month follow-up. J Clin Child Adolesc Psychol 2013;42(4):481-495 [FREE Full text] [doi: 10.1080/15374416.2012.736356] [Medline: 23148530]

13. Kleiman EM, Turner BJ, Fedor S, Beale EE, Huffman JC, Nock MK. Examination of real-time fluctuations in suicidal ideation and its risk factors: Results from two ecological momentary assessment studies. J Abnorm Psychol 2017 Aug;126(6):726-738. [doi: 10.1037/abn0000273] [Medline: 28481571]

14. Nock MK, Prinstein MJ, Sterba SK. Revealing the form and function of self-injurious thoughts and behaviors: A real-time ecological assessment study among adolescents and young adults. J Abnorm Psychol 2009 Nov;118(4):816-827 [FREE Full text] [doi: 10.1037/a0016948] [Medline: 19899851]

15. Kleiman EM, Nock MK. Real-time assessment of suicidal thoughts and behaviors. Curr Opin Psychol 2018 Aug;22:33-37. [doi: 10.1016/j.copsyc.2017.07.026] [Medline: 30122275]

16. Kleiman EM, Turner BJ, Fedor S, Beale EE, Picard RW, Huffman JC, et al. Digital phenotyping of suicidal thoughts. Depress Anxiety 2018 Jul;35(7):601-608. [doi: 10.1002/da.22730] [Medline: 29637663]

17. Millner AJ, Lee MD, Nock MK. Describing and measuring the pathway to suicide attempts: A preliminary study. Suicide Life Threat Behav 2017 Jun;47(3):353-369. [doi: 10.1111/sltb.12284] [Medline: 27477787]

18. Hallensleben N, Glaesmer H, Forkmann T, Rath D, Strauss M, Kersting A, et al. Predicting suicidal ideation by interpersonal variables, hopelessness and depression in real-time. An ecological momentary assessment study in psychiatric inpatients with depression. Eur Psychiatry 2019 Feb;56:43-50. [doi: 10.1016/j.eurpsy.2018.11.003] [Medline: 30530103 ]

19. Bakker D, Kazantzis N, Rickwood D, Rickard N. Mental health smartphone apps: Review and evidence-based recommendations for future developments. JMIR Ment Health 2016 Mar 01;3(1):e7 [FREE Full text] [doi: 10.2196/mental.4984] [Medline: 26932350]

20. Jaroszewski AC, Morris RR, Nock MK. Randomized controlled trial of an online machine learning-driven risk assessment and intervention platform for increasing the use of crisis services. J Consult Clin Psychol 2019 Apr;87(4):370-379. [doi: 10.1037/ccp0000389] [Medline: $\underline{30883164]}$

21. Pauwels K, Aerts S, Muijzers E, De Jaegere E, van Heeringen K, Portzky G. BackUp: Development and evaluation of a smart-phone application for coping with suicidal crises. PLoS One 2017;12(6):e0178144 [FREE Full text] [doi: 10.1371/journal.pone.0178144] [Medline: 28636617]

22. de la Torre I, Castillo G, Arambarri J, López-Coronado M, Franco MA. Mobile apps for suicide prevention: Review of virtual stores and literature. JMIR Mhealth Uhealth 2017 Oct 10;5(10):e130 [FREE Full text] [doi: 10.2196/mhealth.8036] [Medline: 29017992]

23. Kreuze E, Jenkins C, Gregoski M, York J, Mueller M, Lamis DA, et al. Technology-enhanced suicide prevention interventions: A systematic review. J Telemed Telecare 2016 Jul 03;23(6):605-617. [doi: 10.1177/1357633x16657928] 
24. Nuij C, van Ballegooijen W, Ruwaard J, de Beurs D, Mokkenstorm J, van Duijn E, et al. Smartphone-based safety planning and self-monitoring for suicidal patients: Rationale and study protocol of the CASPAR (Continuous Assessment for Suicide Prevention And Research) study. Internet Interv 2018 Sep;13:16-23 [FREE Full text] [doi: 10.1016/j.invent.2018.04.005] [Medline: 30206514]

25. Christensen H, Batterham P, O'Dea B. E-health interventions for suicide prevention. Int J Environ Res Public Health 2014 Aug 12;11(8):8193-8212 [FREE Full text] [doi: 10.3390/ijerph110808193] [Medline: 25119698]

26. Inagaki M, Kawashima Y, Kawanishi C, Yonemoto N, Sugimoto T, Furuno T, et al. Interventions to prevent repeat suicidal behavior in patients admitted to an emergency department for a suicide attempt: A meta-analysis. J Affect Disord 2015 Apr 01;175:66-78. [doi: 10.1016/j.jad.2014.12.048] [Medline: 25594513]

27. Hogan MF. Better suicide screening and prevention are possible. JAMA Psychiatry 2016 Nov 01;73(11):1111-1112. [doi: 10.1001/jamapsychiatry.2016.2411] [Medline: 27706485]

28. Linehan MM, Comtois KA, Murray AM, Brown MZ, Gallop RJ, Heard HL, et al. Two-year randomized controlled trial and follow-up of dialectical behavior therapy vs therapy by experts for suicidal behaviors and borderline personality disorder. Arch Gen Psychiatry 2006 Jul;63(7):757-766. [doi: 10.3410/f.14771.472298]

29. Larsen ME, Nicholas J, Christensen H. A systematic assessment of smartphone tools for suicide prevention. PLoS One 2016 Apr 13;11(4):e0152285 [FREE Full text] [doi: 10.1371/journal.pone.0152285] [Medline: 27073900]

30. Melvin GA, Gresham D, Beaton S, Coles J, Tonge BJ, Gordon MS, et al. Evaluating the feasibility and effectiveness of an Australian safety planning smartphone application: A pilot study within a tertiary mental health service. Suicide Life Threat Behav 2019 Jun;49(3):846-858 [FREE Full text] [doi: 10.1111/sltb.12490] [Medline: 29999193]

31. Torous J, Larsen ME, Depp C, Cosco TD, Barnett I, Nock MK, et al. Smartphones, sensors, and machine learning to advance real-time prediction and interventions for suicide prevention: A review of current progress and next steps. Curr Psychiatry Rep 2018 Jun 28;20(7):51. [doi: 10.1007/s11920-018-0914-y] [Medline: 29956120]

32. Stoyanov SR, Hides L, Kavanagh DJ, Zelenko O, Tjondronegoro D, Mani M. Mobile app rating scale: A new tool for assessing the quality of health mobile apps. JMIR Mhealth Uhealth 2015 Mar 11;3(1):e27 [FREE Full text] [doi: 10.2196/mhealth.3422] [Medline: 25760773]

33. Sheehan D, Lecrubier Y, Sheehan KH, Amorim P, Janavs J, Weiller E, et al. The Mini-International Neuropsychiatric Interview (M.I.N.I.): The development and validation of a structured diagnostic psychiatric interview for DSM-IV and ICD-10. J Clin Psychiatry 1998;59 Suppl 20:22-33;quiz 34 [FREE Full text] [Medline: 9881538]

34. Rush A, Trivedi MH, Ibrahim HM, Carmody TJ, Arnow B, Klein DN, et al. The 16-Item Quick Inventory of Depressive Symptomatology (QIDS), Clinician Rating (QIDS-C), and Self-Report (QIDS-SR): A psychometric evaluation in patients with chronic major depression. Biol Psychiatry 2003 Sep;54(5):573-583. [doi: 10.1016/s0006-3223(02)01866-8]

35. Posner K, Brown GK, Stanley B, Brent DA, Yershova KV, Oquendo MA, et al. The Columbia-Suicide Severity Rating Scale: Initial validity and internal consistency findings from three multisite studies with adolescents and adults. Am J Psychiatry 2011 Dec;168(12):1266-1277 [FREE Full text] [doi: 10.1176/appi.ajp.2011.10111704] [Medline: 22193671]

36. Weisman AD, Worden JW. Risk-rescue rating in suicide assessment. Arch Gen Psychiatry 1972 Jun;26(6):553-560. [doi: 10.1001/archpsyc.1972.01750240065010] [Medline: 5027119]

37. Beck AT, Kovacs M, Weissman A. Assessment of suicidal intention: The Scale for Suicide Ideation. J Consult Clin Psychol 1979;47(2):343-352. [doi: 10.1037/0022-006x.47.2.343]

38. Bernstein DP, Stein JA, Newcomb MD, Walker E, Pogge D, Ahluvalia T, et al. Development and validation of a brief screening version of the Childhood Trauma Questionnaire. Child Abuse Negl 2003 Feb;27(2):169-190. [doi:

10.1016/s0145-2134(02)00541-0]

39. Russell D, Peplau LA, Cutrona CE. The revised UCLA Loneliness Scale: Concurrent and discriminant validity evidence. J Pers Soc Psychol 1980 Sep;39(3):472-480. [doi: 10.1037/0022-3514.39.3.472]

40. Steptoe A, Shankar A, Demakakos P, Wardle J. Social isolation, loneliness, and all-cause mortality in older men and women. Proc Natl Acad Sci U S A 2013 Apr 09;110(15):5797-5801. [doi: 10.1073/pnas.1219686110] [Medline: 23530191]

41. Beck AT, Weissman A, Lester D, Trexler L. The measurement of pessimism: The hopelessness scale. J Consult Clin Psychol 1974 Dec;42(6):861-865. [doi: 10.1037/h0037562] [Medline: 4436473]

42. Linehan MM, Goodstein JL, Nielsen SL, Chiles JA. Reasons for staying alive when you are thinking of killing yourself: The Reasons for Living Inventory. J Consult Clin Psychol 1983;51(2):276-286. [doi: 10.1037/0022-006x.51.2.276]

43. Whiteside SP, Lynam DR, Miller JD, Reynolds SK. Validation of the UPPS impulsive behaviour scale: A four-factor model of impulsivity. Eur J Pers 2005 Dec;19(7):559-574. [doi: 10.1002/per.556]

44. Dan-Glauser ES, Scherer KR. The Difficulties in Emotion Regulation Scale (DERS). Swiss J Psychol 2013 Jan;72(1):5-11. [doi: 10.1024/1421-0185/a000093]

45. Guédeney N, Fermanian J, Bifulco A. Construct validation study of the Relationship Scales Questionnaire (RSQ) on an adult sample [Article in French]. Encephale 2010 Feb;36(1):69-76. [doi: 10.1016/j.encep.2008.12.006] [Medline: 20159199]

46. Van Orden KA, Cukrowicz KC, Witte TK, Joiner TE. Thwarted belongingness and perceived burdensomeness: Construct validity and psychometric properties of the Interpersonal Needs Questionnaire. Psychol Assess 2012 Mar;24(1):197-215 [FREE Full text] [doi: 10.1037/a0025358] [Medline: 21928908] 
47. Ware JE, Sherbourne CD. The MOS 36-ltem Short-Form Health Survey (SF-36). Med Care 1992;30(6):473-483. [doi: 10.1097/00005650-199206000-00002]

48. Morgan J, Farsides T. Measuring meaning in life. J Happiness Stud 2007 Sep 25;10(2):197-214. [doi: 10.1007/s10902-007-9075-0]

49. Maheu MM, Nicolucci V, Pulier ML, Wall KM, Frye TJ, Hudlicka E. The Interactive Mobile App Review Toolkit (IMART): A clinical practice-oriented system. J Technol Behav Sci 2016 Dec 15;1(1-4):3-15. [doi: 10.1007/s41347-016-0005-z]

50. Birnbaum F, Lewis D, Rosen RK, Ranney ML. Patient engagement and the design of digital health. Acad Emerg Med 2015 Jun;22(6):754-756 [FREE Full text] [doi: 10.1111/acem.12692] [Medline: 25997375]

51. Baker TB, Gustafson DH, Shah D. How can research keep up with eHealth? Ten strategies for increasing the timeliness and usefulness of eHealth research. J Med Internet Res 2014 Feb 19;16(2):e36 [FREE Full text] [doi: 10.2196/jmir.2925] [Medline: 24554442]

52. Biagianti B, Hidalgo-Mazzei D, Meyer N. Developing digital interventions for people living with serious mental illness: Perspectives from three mHealth studies. Evid Based Ment Health 2017 Nov;20(4):98-101 [FREE Full text] [doi: 10.1136/eb-2017-102765] [Medline: 29025862]

53. Hawton K, Witt KG, Taylor Salisbury TL, Arensman E, Gunnell D, Townsend E, et al. Interventions for self-harm in children and adolescents. Cochrane Database Syst Rev 2015 Dec 21(12):CD012013. [doi: 10.1002/14651858.CD012013] [Medline: 26688129]

54. Stallard P, Porter J, Grist R. A smartphone app (BlueIce) for young people who self-harm: Open phase 1 pre-post trial. JMIR Mhealth Uhealth 2018 Jan 30;6(1):e32 [FREE Full text] [doi: 10.2196/mhealth.8917] [Medline: 29382632]

55. Franco-Martín MA, Muñoz-Sánchez JL, Sainz-de-Abajo B, Castillo-Sánchez G, Hamrioui S, de la Torre-Díez I. A systematic literature review of technologies for suicidal behavior prevention. J Med Syst 2018 Mar 05;42(4):71. [doi:

10.1007/s10916-018-0926-5] [Medline: 29508152]

56. Krueger RA, Casey AM. Focus Groups: A Practical Guide for Applied Research. 5th edition. Thousand Oaks, CA: SAGE Publications; 2015.

57. Santini ZI. The Impact of Social Networks and Social Support on Mental Disorders and Mortality [doctoral thesis]. Barcelona, Spain: University of Barcelona; 2016. URL: https://portal.findresearcher.sdu.dk/files/123588781/

Ziggi Santini The impact of social networks and social support on mental disorders and mortality.pdf [accessed 2020-09-27]

58. Whitlock J, Wyman PA, Moore SR. Connectedness and suicide prevention in adolescents: Pathways and implications. Suicide Life Threat Behav 2014 Jun;44(3):246-272. [doi: 10.1111/sltb.12071] [Medline: 24444252]

59. Nurullah AS. Received and provided social support: A review of current evidence and future directions. Am J Health Stud 2012;27(3):173-188 [FREE Full text]

60. McDougall MA, Walsh M, Wattier K, Knigge R, Miller L, Stevermer M, et al. The effect of social networking sites on the relationship between perceived social support and depression. Psychiatry Res 2016 Dec 30;246:223-229. [doi: 10.1016/j.psychres.2016.09.018] [Medline: 27721061]

61. Conejero I, Olié E, Calati R, Ducasse D, Courtet P. Psychological pain, depression, and suicide: Recent evidences and future directions. Curr Psychiatry Rep 2018 Apr 05;20(5):33. [doi: 10.1007/s11920-018-0893-z] [Medline: 29623441]

62. Morgiève M, Ung Y, Gehamy C, Briffault X. Diminuer l'impact des troubles obsessionnels compulsifs par des modifications de l'environnement physique: Une étude de preuve de concept (Decrease the impact of obsessive-compulsive disorders through changes in the physical environment: A proof-of-concept study). Psychiatr Sci Hum Neurosci 2016;14:43-63 [FREE Full text] [doi: 10.3917/psn.143.0043]

63. Donkin L, Christensen H, Naismith SL, Neal B, Hickie IB, Glozier N. A systematic review of the impact of adherence on the effectiveness of e-therapies. J Med Internet Res 2011 Aug 05;13(3):e52 [FREE Full text] [doi: 10.2196/jmir.1772] [Medline: 21821503]

64. Kelders SM, Kok RN, Ossebaard HC, Van Gemert-Pijnen JE. Persuasive system design does matter: A systematic review of adherence to web-based interventions. J Med Internet Res 2012 Nov 14;14(6):e152 [FREE Full text] [doi: 10.2196/jmir.2104] [Medline: 23151820]

65. Smith W, Ploderer B, Wadley G, Webber S, Borland R. Trajectories of engagement and disengagement with a story-based smoking cessation app. In: Proceedings of the 2017 CHI Conference on Human Factors in Computing Systems (CHI '17). 2017 May Presented at: 2017 CHI Conference on Human Factors in Computing Systems (CHI '17); May 6-11, 2017; Denver, CO p. 3045-3056. [doi: 10.1145/3025453.3026054]

66. Sieverink F, Kelders SM, van Gemert-Pijnen JE. Clarifying the concept of adherence to eHealth technology: Systematic review on when usage becomes adherence. J Med Internet Res 2017 Dec 06;19(12):e402 [FREE Full text] [doi: 10.2196/jmir.8578] [Medline: 29212630]

67. Andreasson K, Krogh J, Bech P, Frandsen H, Buus N, Stanley B, et al. MYPLAN_mobile phone application to manage crisis of persons at risk of suicide: Study protocol for a randomized controlled trial. Trials 2017 Apr 11;18(1):171 [FREE Full text] [doi: 10.1186/s13063-017-1876-9] [Medline: 28399909]

68. Coppersmith G, Ngo K, Leary R, Wood A. Exploratory analysis of social media prior to a suicide attempt. In: Proceedings of the Third Workshop on Computational Linguistics and Clinical Psychology. 2016 Jun Presented at: Third Workshop on 
Computational Linguistics and Clinical Psychology; June 16, 2016; San Diego, CA p. 106-117 URL: https://www.aclweb.org/ anthology/W16-0311.pdf [doi: 10.18653/v1/w16-0311]

69. Spangenberg L, Forkmann T, Glaesmer H. Investigating dynamics and predictors of suicidal behaviors using ambulatory assessment. Neuropsychiatr 2015;29(3):139-143. [doi: 10.1007/s40211-015-0142-1] [Medline: 25868681]

70. Davidson CL, Anestis MD, Gutierrez PM. Ecological momentary assessment is a neglected methodology in suicidology. Arch Suicide Res 2017 Jan 02;21(1):1-11. [doi: 10.1080/13811118.2015.1004482] [Medline: 26821811]

71. Bagge CL, Littlefield AK, Glenn CR. Trajectories of affective response as warning signs for suicide attempts. Clin Psychol Sci 2017 Mar 13;5(2):259-271. [doi: 10.1177/2167702616681628]

72. Briffault X, Morgiève M, Courtet P. From e-Health to i-Health: Prospective reflexions on the use of intelligent systems in mental health care. Brain Sci 2018 May 31;8(6):98 [FREE Full text] [doi: 10.3390/brainsci8060098] [Medline: 29857495]

73. Nahum-Shani I, Smith SN, Spring BJ, Collins LM, Witkiewitz K, Tewari A, et al. Just-in-time adaptive interventions (JITAIS) in mobile health: Key components and design principles for ongoing health behavior support. Ann Behav Med 2018 May 18;52(6):446-462 [FREE Full text] [doi: 10.1007/s12160-016-9830-8] [Medline: 27663578]

74. Linthicum KP, Schafer KM, Ribeiro JD. Machine learning in suicide science: Applications and ethics. Behav Sci Law 2019 May;37(3):214-222. [doi: 10.1002/bsl.2392] [Medline: 30609102]

75. Kilsdonk E, Peute L, Jaspers M. Factors influencing implementation success of guideline-based clinical decision support systems: A systematic review and gaps analysis. Int J Med Inform 2017 Feb;98:56-64. [doi: 10.1016/j.ijmedinf.2016.12.001] [Medline: 28034413]

\author{
Abbreviations \\ Medicines and Health Products Safety) \\ C-SSRS: Columbia-Suicide Severity Rating Scale \\ DSM-5: Diagnostic and Statistical Manual of Mental Disorders, 5th Edition \\ ED: emergency department \\ EMA: ecological momentary assessment \\ EMI: ecological momentary intervention \\ EMMA: Ecological Mental Momentary Assessment \\ M0: month 0 (inclusion) \\ M1: month 1 \\ M3: month 3 \\ M6: month 6 \\ mHealth: mobile health \\ NERB: Neurophysiology of Repetitive Behaviors \\ SAMU: Service d'Aide Médicale d'Urgence \\ WHO: World Health Organization
}

ANSM: Agence Nationale de Sécurité du Médicament et des Produits de Santé (French National Agency for

\author{
Edited by G Eysenbach, R Leung; submitted 19.09.19; peer-reviewed by L Giner, D Hilty, J Sussman, B Renn, G Klein, D Bakker, $M$ \\ Businelle; comments to author 12.02.20; revised version received 08.04.20; accepted 03.06.20; published 09.10.20 \\ Please cite as: \\ Morgiève M, Genty C, Azé J, Dubois J, Leboyer M, Vaiva G, Berrouiguet S, Courtet P \\ A Digital Companion, the Emma App, for Ecological Momentary Assessment and Prevention of Suicide: Quantitative Case Series \\ Study \\ JMIR Mhealth Uhealth 2020;8(10):e15741 \\ URL: https://mhealth.jmir.org/2020/10/e15741 \\ doi: 10.2196/15741 \\ PMID: $\underline{3034567}$
}

CMargot Morgiève, Catherine Genty, Jérôme Azé, Jonathan Dubois, Marion Leboyer, Guillaume Vaiva, Sofian Berrouiguet, Philippe Courtet. Originally published in JMIR mHealth and uHealth (http://mhealth.jmir.org), 09.10.2020. This is an open-access article distributed under the terms of the Creative Commons Attribution License (https://creativecommons.org/licenses/by/4.0/), which permits unrestricted use, distribution, and reproduction in any medium, provided the original work, first published in JMIR mHealth and uHealth, is properly cited. The complete bibliographic information, a link to the original publication on http://mhealth.jmir.org/, as well as this copyright and license information must be included. 